\title{
REPORT
}

\section{Combustion Byproducts and Their Health Effects: Summary of the 10th International Congress}

\author{
Barry Dellinger, ${ }^{1, \star}$ Antonio D'Alessio, ${ }^{2}$ Andrea D'Anna, ${ }^{2}$ Anna Ciajolo, ${ }^{3}$ Brian Gullett, ${ }^{4}$ Heather Henry, ${ }^{5}$ \\ Mel Keener, ${ }^{6}$ JoAnn Lighty, ${ }^{7}$ Slawomir Lomnicki, ${ }^{1}$ Donald Lucas, ${ }^{8}$ Günter Oberdörster, ${ }^{9}$ Demetrio Pitea, ${ }^{10}$ \\ William Suk, ${ }^{5}$ Adel Sarofim, ${ }^{7}$ Kirk R. Smith, ${ }^{11}$ Tobias Stoeger, ${ }^{12}$ Paige Tolbert, ${ }^{13}$ Ron Wyzga, ${ }^{14}$ \\ and Ralf Zimmermann ${ }^{12,15}$ \\ ${ }^{1}$ Department of Chemistry, Louisiana State University, Baton Rouge, LA \\ 2Dipartimento di Ingegneria Chimica, Università degli Studi di Napoli "Federico II", Napoli, Italy \\ 3/stituto Ricerche Combustione, CNR, Napoli, Italy \\ ${ }^{4}$ U.S. Environmental Protection Agency, Office of Research and Development, Research Triangle Park, NC \\ ${ }^{5}$ Division of Extramural Research and Training, NIEHS, Research Triangle Park, NC \\ ${ }^{6} \mathrm{CRWI}$, Washington, DC \\ ${ }^{7}$ Department of Chemical Engineering, University of Utah, Salt Lake City, UT \\ ${ }^{8}$ School of Public Health, University of California, Berkeley, Environmental Health and Safety Division, \\ Lawrence Berkeley National Laboratory, Berkeley, CA \\ ${ }^{9}$ Department of Environmental Medicine, University of Rochester, Rochester, NY \\ ${ }^{10}$ Dipartimento di Scienze Ambientali, Università degli Studi di Milano Bicocca, \\ Piazza della Scienza 1, Milano, Italy \\ ${ }^{11}$ School of Public Health, University of California, Berkeley, CA \\ ${ }^{12}$ Hemholtz Zentrum München, German Research Center for Environmental Health, \\ Institute of Ecological Chemistry, D-85764 Oberschleissheim, Germany \\ ${ }^{13}$ Rollins School of Public Health, Emory University, Atlanta, GA \\ ${ }^{14}$ Electric Power Research Institute, Palo Alto, CA \\ ${ }^{15}$ University Rostock, Institute of Chemistry, Chair of Analytical Chemistry, D-18051 Rostock, Germany
}

\begin{abstract}
The 10th International Congress on Combustion Byproducts and their Health Effects was held in Ischia, Italy, from June 17-20, 2007. It is sponsored by the US NIEHS, NSF, Coalition for Responsible Waste Incineration (CRWI), and Electric Power Research Institute (EPRI). The congress focused on: the origin, characterization, and health impacts of combustion-generated fine and ultrafine particles; emissions of mercury and dioxins, and the development/application of novel analytical/diagnostic tools. The consensus of the discussion was that particle-associated organics, metals, and persistent free radicals (PFRs) produced by combustion sources are the likely source of the observed health impacts of airborne PM rather than simple physical irritation of the particles. Ultrafine particle-induced oxidative stress is a likely progenitor of the observed health impacts, but important biological and chemical details and possible catalytic cycles remain unresolved. Other key conclusions were: (1) In urban settings, $70 \%$ of airborne fine particles are a result of combustion emissions and $50 \%$ are due to primary emissions from combustion sources, (2) In addition to soot, combustion produces one, possibly two, classes of nanoparticles with mean diameters of $\sim 10 \mathrm{~nm}$ and $\sim 1 \mathrm{~nm}$. (3) The most common metrics used to describe particle toxicity, viz. surface area, sulfate concentration, total carbon, and organic carbon, cannot fully explain observed health impacts, (4) Metals contained in combustion-generated ultrafine and fine particles mediate formation of toxic air pollutants such as PCDD/F and PFRs. (5) The combination of metal-containing nanoparticles, organic carbon compounds, and PFRs can lead to a cycle generating oxidative stress in exposed organisms.
\end{abstract}

Key words: products of incomplete combustion; PICs, biomass combustion; persistent free radicals; particulate matter; soot; NOC; nanoparticles; ultrafine particles; dioxins; mercury; tobacco smoke

*Corresponding author: Louisiana State University, Chemistry Department, 413 Choppin Hall, Baton Rouge, LA 70803. Phone: 225-5786759; Fax: 225-578-0276; E-mail: barryd@lsu.edu 


\section{Introduction}

T He 10th International Congress on Combustion Byproducts and Their Health Effects was held in Ischia, Italy, from June 17-20, 2007. The delegates to the Congress were academic and government researchers, industrial engineers/scientists, and policy makers. Since its inception in 1990, the goal of the Congress has been to interface the disciplines of combustion and toxicological research to better understand and mitigate the human health and environmental impacts of emissions of toxic combustion byproducts.

This Congress focused on international environmental health issues. The environmental impacts of combustion of biomass (e.g., wood stoves for cooking or heating and agricultural burning) emerged as a critical, world-wide, environmental issue. Four classes of pollutants were most discussed: (1) combustion-generated particulate matter (PM), (2) polychlorinated dibenzo- $p$-dioxins and dibenzofurans (PCDDs/Fs), (3) polycyclic aromatic hydrocarbons (PAHs) and their derivatives, and (4) environmentally persistent free radicals (PFRs). Although not as well studied as the particles from fossil fuel combustion, there is no persuasive evidence that biomass smoke particles are less toxic to humans (Naeher et al., 2007). However, the origin of its toxicity is poorly understood at best. Because of the heterogeneity of biomass and because most burning occurs with poor combustion efficiency, it can produce carbonaceous PM, inorganic PM, hydrocarbons and $\mathrm{PAH}$, oxy-hydrocarbons and oxy-PAH, chlorinated hydrocarbons (CHCs), and PFRs. The health impacts of many of these pollutants are not well characterized as individual chemicals, and the modification of their toxicity as a result of association with PM is virtually unknown. Hence, the information exchange between toxicology, health effects, and combustion engineers is necessary to fully understand the human health impacts of toxic combustion byproducts.

\section{Environmental and Health Impacts of Combustion}

The dangers of pollution in urban areas have been long recognized, if not remedied. The first recorded governmental attempt to address air pollution issues was the appointment of the Royal Air Pollution Commission in England in 1265. The Commission completed its report in 1306 (having met for 41 years) and recommended banning coal burning in London (Brimblecombe, 1987). Such a ban was not implemented by authorities until the 1950s, some 650 years later-a poor example of bureaucratic response to say the least. Fortunately, the global community is now more generally concerned with the health impacts of combustion with the concomitant development of pollutant characterization methods, understanding the sources and creation of air pollution, development of basic metrics for assessment of risk, and setting of appropriate health standards.

Although much interest has been placed on pollution in urban areas, the exposure of individuals in rural areas continues to be an area of major concern. Many of the developing world populations (e.g., India and China) use unvented biomass stoves for cooking and heating in tightly confined dwellings. Depending on how it is burned, wood produces fine particles (FPs, or $\mathrm{PM}_{2.5}$, with a mass mean diameter of less than 2.5 micrometer) at $0.1-0.4 \%$ by weight of fuel, as well aliphatic/olefinic hydrocarbons, aromatic hydrocarbons and $\mathrm{PAH}$, oxy-hydrocarbons and oxy-PAH, and CHCs. Butadiene, benzene, benzo(a)pyrene, catechols/hydroquinones/semiquinones, and PCDD/F have all been identified in wood smoke (Naeher et al., 2007). Even in many developed countries, biomass smoke is still important. Recent air quality studies in Augsburg Germany, for example, suggest that the majority of the PAH content of ambient PM2.5 originated from wood combustion (Sklorz et al., 2007a; Schnelle-Kreis 2007).

Studies have shown that children in households using solid fuels have twice the normal rate of serious acute lower respiratory infection (ALRI) (Smith et al., 2004). ALRI is the single greatest cause of death of the world's children $(>2$ million/year), and accepted risk factors such as malnutrition and crowding do not fully account for this death rate. The other major disease that closely associates with these exposures is chronic obstructive pulmonary disease (COPD) in adult women, a major source of morbidity and premature mortality globally (Bruce et al., 2000). The impact of indoor solid fuel smoke on these two diseases brings it to 10 th $(\sim 1.5$ million premature deaths/year) as a risk factor for the global burden of disease, compared for example to active tobacco smoking, which is rated fourth (4.9 million deaths/yr) (WHO, 2002). Although ALRI and COPD are the best documented, other effects are also observed, for example, increased blood pressure (McCracken et al., 2007) and cataracts (Pokhrel et al., 2005).

Similar types of health effects are found from exposures to the combustion byproducts of biomass fuels and tobacco smoke, the most well studied being those due to exposure to biomass combustion byproducts. Although exposure to environmental tobacco smoke is a serious health concern with well-documented effects, exposure to PM produced from biomass fuel combustion is even more universal, and has an even greater health and environmental impact, although the latter is virtually unregulated worldwide.

The global health impacts of combustion are reflected in U.S. epidemiologic studies. Studies of the acute effects of exposure to airborne $\mathrm{PM}_{2.5}$, primarily from fossil fuel combustion, show increased mortality due to respiratory and cardiovascular dysfunction and increased hospitalization/ health care utilization due to COPD, pneumonia, asthma, and cardiovascular disease with increases all in the range of $1-3 \%$ per $5 \mu \mathrm{g} / \mathrm{m}^{3} \mathrm{PM}_{2.5}$ (Pope, 2000). The associations with acute outcomes are caused by 1-5-day exposures, do not exhibit thresholds for onset, and have been observed for various locations, pollutant mixes, weather, and demographics.

As an example of the effects of exposure to particulate matter, in Atlanta, GA, daily counts of emergency department admissions for cardiovascular disease (CVD) are associated with ambient PM2.5 levels (Metzger et al., 2004; Peel et al., 2005). Speciated particle measurements in Atlanta have allowed investigators to assess this association in greater depth and consider aspects of particle composition that may contribute to the health risks. Associations were observed for both the elemental carbon and organic carbon fractions of $\mathrm{PM}_{2.5}$, as well as the gaseous pollutants carbon monoxide and nitrogen dioxide. Source apportionment using Positive Matrix Factorization (PMF) and Chemical Mass Balance (CMB) suggested CVD visits were most strongly related to $\mathrm{PM}_{2.5}$ from diesel exhaust, gasoline emissions, and biomass combustion (Marmur, 2006; Sarnat, in press). 
Such investigations provide insights into the physical and chemical attributes of particulate matter that may underlie the consistently observed health effects of fine particles. However, given the complexity of the mechanisms involved, interactions among pollutants (e.g., PM components) and different agents operating on different time scales, covariation of ambient levels of different pollutants of interest, differing levels of measurement error across pollutants and the possibility that a pollutant may serve as a surrogate for other pollutants, a full understanding of the etiologic relationships is a challenging goal to achieve. Other approaches that are complementary to epidemiologic investigations offer additional characterization of particles and elucidation of these complex relationships as presented subsequently in these proceedings.

\section{Combustion-Generated Nanoparticles}

Health effect and epidemiologic studies clearly indicate an association between increased mortality/morbidity rates and exposure to airborne fine particles. However, the responsible pollutants have not been identified. Because $70 \%$ of airborne fine particles are a result of combustion emissions, research on the nature of combustion emissions is paramount.

Approximately $35 \%$ of airborne $\mathrm{PM}_{2.5}$ is organic and elemental carbon (Chow et al., 1996). Airborne particles a diameter of less than $0.1 \mu \mathrm{m}\left(\mathrm{PM}_{0.1}\right)$ are typically referred to as ultrafine particles (UFPs) by the environmental community and, alternatively, nanoparticles by the combustion engineering and scientific communities. For typical nanoparticles, the organic carbon content increases to 50\% (Kleeman et al., 2000), with the balance of the particle composed of elemental carbon, metal oxides, sulfates, nitrates, ammonium, and sodium (Cass et al., 2000).

Although the exact proportion is not known, it is clear that the majority of airborne fine and ultrafine particles are combustion generated or combustion derived. Combustion-generated particles are direct primary emissions and include soot and other particles formed by nucleation. Combustion-derived particles include particles with high sulfate or nitrate content that are formed by secondary atmospheric reactions catalyzed by combustion-generated particles.

It has long been known that soot consists primarily of micron-sized, fractal aggregates of 20-50-nm nanoparticle spheres (Megaridis and Dobbins, 1989). Much effort has been expended on mapping soot formation in different types of flames and combustors. Reasonable models have been developed to explain aggregation. Models have also been developed that explain formation of large PAH from small hydrocarbon species. However, the understanding of how large PAH molecules, with a molecular mass of $<1,000$ AMU and containing $\sim 100$ carbon atoms (equivalent spherical size of about $1 \mathrm{~nm}$ ), grow to $20 \mathrm{~nm}$ spheres containing $\sim 1,000,000$ carbon atoms is unclear. Fortunately, the development of new measurement methods has yielded some useful results.

Light scattering and extinction measurements in flames have revealed the presence of additional particles smaller than soot with a mass mean diameter of $\sim 2 \mathrm{~nm}$, referred to as nano-organic carbon (NOC). Based on in situ optical measurements as well as atomic force microscopy (AFM), the particle diameter distribution of nanoparticles is clearly bimodal with one mode, NOC, centered at a few nanometers and the second (soot) centered at a few tens of nanometers. Differential mobility analyzer data hints at the existence of NOC in a third type of particle with a mass mean diameter of less than $1 \mathrm{~nm}$, suggesting that combustion-generated nanoparticles are trimodal.

These findings lead one to question how these particles are linked and how they may be related to traditional models of molecular growth through PAHs to form soot. Although, the prevailing theory is that PAHs are intermediates in the formation of soot, it has been suggested that PAHs are formed by separate dead-end pathways. This question can now be extended to the three types of particles: are the smaller NOC particles intermediates in the formation of soot or are they dead-end products? Even more fundamentally: are they formed by the same mechanism? These questions are difficult to answer because we do not even know if these particles are chemically similar. Their major component is carbon, but trace inorganics including nonvolatile condensation nuclei such as sulfates, metal counteranions such as sodium, or catalytic transition metals such as iron may play a role in their formation, subsequent chemistry, and toxicology.

While it is convenient to think of these nanoparticles as homogeneous and formed by homogeneous nucleation pathways, this is not necessarily the case. There is always a competition between homogeneous nucleation and surface condensation on an already formed particle, the latter possibly inactivating the particles toward further growth (Kittelson et al., 1999; Maricq et al., 1999). For example, semivolatile hydrocarbons may condense on nanoparticles forming a liquid or semiliquid layer. A sulfuric acid or metal sulfate layer may be formed by iron catalyzed oxidation of sulfur dioxide to sulfur trioxide, which in the presence of water and metal ions such as sodium or calcium forms the corresponding sulfate and results in particles $\sim 100 \mathrm{~nm}$ in diameter.

It is clear from the particle characterization work that the key to understanding the origin and nature of combustiongenerated nanoparticles is the chemical composition and associated chemistry. Not only is the carbon-hydrogen ratio important, but also the oxygen content, transition metal content, and inorganic anion/cation content. However, only limited chemical characterization is available.

Organic carbon (OC) is used as an indicator of physi- or chemisorbed organic materials. The OC fraction of total carbon (TC) approaches $0.9-1.0$ as combustion approaches stoichiometric conditions with higher equivalence ratios (fuel rich) favoring increased OC content (Gardner et al., 2005). These data suggest that oxygen is required for conversion of organic carbon to elemental carbon, which could be considered counterintuitive, because oxygen is normally thought to oxidize organics to carbon dioxide rather than reduce them to EC.

This interpretation is supported by the observation of significant amounts of oxygen in NOC by Surface Enhanced Raman Spectroscopy (SERS). SERS has been used to tentatively identify $\mathrm{C}-\mathrm{O}-\mathrm{C}$, and $\mathrm{O}-\mathrm{O}$ bonds in NOC. Such weak bonds would appear unlikely in particles formed at high temperature. This suggests that the particles are formed at lower temperature under more oxidizing conditions or the observed low energy SERS bands are due to other types of stronger bonds such as C-O-metal bonds. Such an interpretation is 
possible, as it has been observed that when metals are vaporized in a flame, they condense to form nanoparticles in the 2-20-nm size regime (Allouis et al., 2003). Nuclear magnetic resonance (NMR) has been used to detect the usual $\mathrm{PAH}$, but has also detected more oxygen-containing compounds, including phenolics, alcohols, carbonyls, and esters (D'Anna et al., 2001; Pugmire et al., 2002).

The observation of NOC has proven important as the atmospheric extinction spectrum can be reproduced from known combustion emissions only if NOC is included (D'Anna et al., 2005). Interestingly, both NOC and soot have been observed in diesel exhaust, while spark ignited (SI) engines and natural gas combustors form primarily NOC. Furthermore, SI exhaust PM exhibits toxicity similar to that of diesel exhaust particulate (DEP) in mouse embryo fiberblasts. Since SI exhaust contains primarily NOC under normal driving conditions, and DEP contains both NOC and soot, NOC alone may be responsible for the observed toxicity of both DEP and soot.

The smallest NOC is very hydrophilic and does not coagulate. These properties suggest that NOC may be transported by a wet mechanism in the environment. They also suggest that NOC may remain unaggregated under biological conditions and, unless it is dissolved in the lung media, be readily transported as particles to organs other than the lung. These properties may also facilitate further research on NOC by providing a method of separation of NOC from soot (which is hydrophobic and aggregates). Clearly, the toxicity of NOC and its role in soot formation must be a research priority, and one might now question if the toxicity reported for soot is actually due to the toxicity of associated NOC.

\section{Combustion-Generated Non-PM Air Pollutants}

Until relatively recently, research on the origin of combustion-generated air pollution has focused on the gas-phase pathways of formation of soot and other air pollutants such as PAH. There were special cases, such as the iron catalyzed oxidation of sulfur dioxide to sulfur trioxide; however, the realization that PCDD/Fs are largely formed by catalyzed reactions on the surfaces of particles has led to increased interest in the surface-mediated formation of organic pollutants. The surface-mediated formation occurs in the postflame, cool zone of combustors in the temperature range of $200-500^{\circ} \mathrm{C}$ with the maximum typically occurring from 280 $350^{\circ} \mathrm{C}$.

Since the mid-1980s there have been two schools of thought on the mechanism of formation of PCDD/Fs in combustion systems. One community largely ascribes to the de novo mechanism in which PCDD/Fs are directly formed via reactions of soot and flyash with oxygen or chlorine in the presence of a copper oxide catalyst. Although the details of the mechanism are poorly understood, it is now generally believed that a nonchlorinated dibenzofuran or dibenzo- $p$ dioxin "skeleton or scaffold" is created from elemental carbon in PM which is then chlorinated to form PCDD/F. It is currently believed that the de novo pathway is actually confined largely to formation of PCDF and not PCDD. The mechanism is thought to involve the dissociative chemisorption of molecular oxygen on carbon followed by gasification of dibenzofurans or other PCDD/F hydrocarbon intermediates such as benzenes and phenols (Collina et al., 2000).
The other community has focused more on the surfacemediated, precursor pathway, for example, formation of PCDD/Fs from chlorinated phenols over a copper oxide surface. While chlorinated phenols do form significant quantities of PCDDs, the PCDD to PCDF ratio is $>1$ which is in contradiction with field data that indicates a ratio of $<<1$ (with the possible exception of biomass burning). This is one reason for the belief that the de novo pathway is responsible for PCDFs while surface-mediated and gas-phase pathways involving more direct progenitors such as chlorophenols are responsible for PCDDs.

However, it has now been demonstrated that chlorinated benzenes react on copper oxide surfaces to form PCDD/Fs. In contrast to chlorinated phenols, chlorinated benzenes form far more PCDFs than PCDDs. This suggests that the surface-mediated precursor pathway may have a major role in the overall formation of PCDD/Fs. Furthermore, it was also demonstrated that iron oxides mediate the formation of PCDD/Fs from chlorinated phenols, and the temperature window for formation of PCDD/F is slightly higher than for copper oxide.

The cool zone formation of PCDD/Fs suggests that development of methods for PCDD/F reduction should focus on the cool zone region of combustion and industrial thermal processes. Reduction in PCDD/F emissions has been achieved by: (1) rapidly quenching the flue gas cool-zone temperature by mixing the flue gases with ambient air, (2) installation of more efficient air pollution control devices (APCDs) for reduction in PM emissions, (3) installation of reactors to increase PM size and improve fabric filter APCD removal efficiency for PM, and (4) addition of activated carbon injection systems to adsorb PCDD/F (Lasagni et al., 1997).

An interesting discovery that has been the result of research on the mechanism of PCDD/F formation has been the discovery of environmentally persistent free radicals associated with combustion-generated PM. It has been observed that substituted benzenes and phenols chemisorb on the surface of copper oxide-containing fine and ultrafine particles and form PFRs. Depending upon the structure of the precursors, these PFRs can be phenols, catechols, or hydroquinones. The resulting radicals can be precursors for PCDD/F formation or persist on the particles as free radicals for more than $24 \mathrm{~h}$ after formation. These PFRs can also induce oxidative stress in exposed organisms. One interesting observation is that when extracted in a strong polar, proton donating solvent such as an alcohol, they are converted to the corresponding molecular species. This finding brings into question whether molecular phenols/catechols/hydroquinones reported to be associated with combustion-generated PM are molecular species or PFRs. The data suggests that they are PFRs, which has significant implications for the toxicology of combustion-generated PM. If the PFRs are chemisorbed to nanoparticles, it may be incorrect to consider the particle and the molecular pollutant as separate entities; rather, they are new types of combustion-generated chemical species.

The development of mass spectrometric methods with soft photo-ionization allows the on-line detection of several traceproducts of combustion. Low-ring-number aromatics and PAH can be detected using laser-based resonance enhanced multiphoton ionization (REMPI) (Oudejans et al., 2004). Lamp 
or laser-based, single photon ionization or single photon ionization by a novel VUV-lamp (electron beam pumped rare gas excimer lamp, EBEL) have proven effective in measurement of aliphatic combustion/pyrolysis products (Mühlberger et al., 2005; Zimmermann, 2005). Recent applications include the highly time resolved analysis of pyrolysis products such as butadiene, acetaldehyde, isoprene, and benzene in tobacco smoke as well as the detection of benzene, toluene, and naphthalene in diesel generator exhausts.

\section{Health Impacts of Combustion-Generated Fine and Ultrafine Particles}

With the results of epidemiologic studies now available, research on the health effects of combustion-generated fine/ ultrafine particles and particle-associated pollutants has increased. If particles are soluble, then the total mass of a given type of particle is an appropriate first metric of exposure. However, if it is insoluble, then surface area of the particle is the more appropriate parameter (Oberdörster et al., 2005).

Most combustion-generated particles are insoluble at physiological $\mathrm{pH}$. Thus, because fine and ultrafine particles have a higher total surface area than coarse particles, they may be of greater health concern. This is amplified by the increased deposition of fine and ultrafine particles in the lower respiratory tract and alveoli that can result in particle translocation to other organs and/or adsorbed pollutants desorbing into the blood stream.

Exposure to ultrafine particles has been associated with respiratory effects (Peters et al., 1997) including asthma (von Klot et al., 2002), reduced lung function in children (Kulkarni et al., 2006), and COPD as well as a $0.1 \%$ increase in risk of lung cancer with exposure to titanium dioxide, carbon black, or DEP (Kuempel et al., 2006).

Much toxicity research has relied on the use of surrogates for ambient UFPs, focusing on primarily carbonaceous UFPs including DEP, soot, and carbon black. These primary particles typically range in mean diameter from 10 to $50 \mathrm{~nm}$, contain 1 to $20 \%$ organic carbon, and have surface areas varying from 40 to $800 \mathrm{~m}^{2} / \mathrm{g}$. In this context, recent studies exposing mice for $24 \mathrm{~h}$ to ultrafine carbon particles affirmed the pro-inflammatory as well as allergy adjuvant properties of these pollutants (Alessandrini et al., 2006; Andre et al., 2006). Proinflammatory effects generally increase with particle surface area. However, they are also enhanced with the presence of high surface-reactivity transition metals (Dick et al., 2003; Oberdörster et al., 2005; Stoeger et al., 2006).

Oxidative stress-induced toxicity has been the focus of most research on the mechanism of toxicity of fine and ultrafine particles (Donaldson et al., 2001). Structural properties of the particle surface, adsorbed organic chemicals, PFRs, and transition metals have all been suggested as possible sources of the particle-induced oxidative stress. However, research has shown that surface area alone cannot explain inflammatory response or oxidative potency in its entirety. Organic carbon concentration also does not explain inflammatory response, which has been attributed to variances in bioavailability of adsorbed organics. Recent results suggest that the oxygen-containing free radical formation potential of PM is correlated to the concentration of oxygenated polycyclic aromatic hydrocarbons (Sklorz et al., 2007b). Bioactivation of some organic carbon compounds by phase I detox- ification enzymes like Cypla1 has also been suggested (Baulig et al., 2003).

Extra-pulmonary effects of exposure to PM include: disturbance of stress response, disturbance of vasomotor function, arrhythmia, endothelial dysfunction and systemic inflammation, pro-coagulative status, atherosclerosis, and even inflammation/neurodegeneration of the central nervous system. For example, rats exposed to high levels of ultrafine carbon particles ( $180 \mu \mathrm{g} / \mathrm{m}^{3}$ for $24 \mathrm{~h}$ ) exhibited increased heart rate, reduced heart rate variability, and increased diastolic blood pressure (Harder et al., 2005), as well as increased plasma levels in the endothelium and asymmetric dimethylarginie (ADMA) (Dvonch et al., 2004; Elder et al., 2004). Rats exposed to transition metal-containing ( $\mathrm{Cu}$ and $\mathrm{Fe}$ ) ultrafine particles exhibited platelet aggregation via the purinergic ADP receptor (P2Y12) and induced fibrinogen receptor activation. They exhibited clear signs for endothelial dysfunction and disturbance of the vegetative balance (as indicated by increased heart rate and reduced heart rate variability) (Harder et al., 2005) as well as increased plasma levels of endothelin and the eNOS inhibitor, ADMA (Dvonch et al., 2004; Elder et al., 2004). Platelet suspensions exposed to transition metal-containing ( $\mathrm{Cu}$ and $\mathrm{Fe}$ ) ultrafine particles exhibited platelet aggregation via the purinergic ADP receptor (P2Y12) (Deb et al., 2007) and carbon nanoparticles induced fibrinogen receptor activation (Radomski et al., 2005). Notably, long-term exposure of atherosclerosis-prone mice to a moderate dose of $85 \mu \mathrm{g} / \mathrm{m}^{3} \mathrm{PM}_{2.5}$ for 6 months caused increased vasomotor tone, vascular inflammation, and increased atherosclerotic plaque development (Sun et al., 2005). Findings from animal exposure studies support epidemiologic associations between exposure to particulate air pollution and an increased risk for myocardial infarction (Peters, 2006).

One interesting theory that brings the concept of particle surface area, reactive transition metals and adsorbed organics together is that of chemisorbed PFRs. Recent research has shown that organics chemisorbed to copper oxide-containing silica nanoparticles induce oxidative stress in vitro and in exposed rats (Cormier et al., 2006). Controls of pure silica nanoparticles, copper oxide-containing nanoparticles, or physisorbed molecular species induced minimal oxidative stress. The PFRs chemisorbed on transition metals can result in a catalytic cycle involving both the PFRs as well as the reduced and oxidized form of the transition metal that converts molecular oxygen to biologically damaging reactive oxygen species (ROS). By being chemically attached to the nanoparticle, transition metal ions and radicals that would not normally pass through the cell membrane's lipid bilayer can be transported inside the cell where they can induce oxidative stress and associated diseases.

\section{Summary}

The presentations and discussions by the delegates at the Congress clearly indicate that the direction of research is integration of the origin and chemical nature of combustiongenerated ultrafine particles and their health impacts. Gasphase species are also important pollutants, but from a combustion perspective, they are more well studied. Gasphase, molecular pollutants, in addition to being potential 
toxicants, can also become associated with fine and ultrafine particles where they interact with the particles to form new free-radical pollutants.

The combustion engineering and science research has demonstrated that nanoparticles contain organics, metals, and PFRs that are the likely source of the observed health impacts of particles rather than simple physical irritation. Ultrafine particle-induced oxidative stress is likely to be an important progenitor of the observed health impacts, but important biological and chemical details and possible catalytic cycles remain unresolved. Gas-phase pollutants undoubtedly contribute to environmentally induced diseases, but an integrated approach to the impacts of gas-phase and particulate-associated pollutants is needed.

Key observations are:

- Exposure to airborne fine particles is associated with increased risk of cardiopulmonary disease and cancer.

- In developed-country urban settings, 70\% of airborne fine particles are a result of combustion emissions and $50 \%$ are due to primary emissions from combustion sources.

- In addition to soot nanoparticle aggregates, combustion can produce one, possibly two, additional classes of particles that are even smaller, with mean diameters of $\sim 10$ $\mathrm{nm}$ and $\sim 1 \mathrm{~nm}$.

- Elemental carbon is the major component of these particles but they also contain organic carbon, sulfur and nitrogen anions, metal cations, transition metals, and PFRs.

- Health effects research strongly suggest that the smaller the particles, the greater the toxicity if the surface chemistries are similar.

- Oxidative stress may be responsible for most of the observed health impacts.

- The most common metrics used to describe particle toxicity, viz. surface area, sulfate concentration, total carbon, and organic carbon, cannot fully explain observed health impacts.

- So-called NOC, with particle diameters of less than $10 \mathrm{~nm}$, contains organic carbon including oxy-hydrocarbons and other inorganic species that may be responsible of induction of oxidative stress.

- Metals contained in combustion-generated ultrafine and fine particles mediate or catalyze formation of toxic air pollutants such as PCDD/F and PFRs.

- The combination of metal-containing nanoparticles, organic carbon compounds, and PFRs can lead to a cycle generating oxidative stress in exposed organisms.

Research in the following areas is recommended:

- Studies of the interaction of gas-phase molecular pollutants with fine and ultrafine particles that result in a repartitioning of the gas-phase species and possible formation of new radical pollutants associated with the surfaces of the particles.

- Development of improved methods for monitoring and measurement of combustion-generated ultrafine particles and toxic trace chemicals.

- Development of methods for sampling and chemical characterization of ultrafine particles for organics, ions, transition metals, and PFRs.
- Comparison of the surface reactivity and product distributions of chemical reactions on combustion-generated particles of different sizes and compositions.

- Epidemiologic studies that correlate incidence of disease with specific chemical components of fine and ultrafine particles.

- Studies of the oxidative stress-induced health impacts of ultrafine particles as a function of organic, ion, transition metal and PFR concentration as well as particle size.

- Application of modern combustion engineering design to development of inexpensive, reliable, low-emission household cooking/heating stoves for poor populations in the developing world.

The 11th International Congress on Combustion Byproducts and their Health Effects will be hosted by the U.S. EPA at its Research Triangle Park, NC, facility in June 2009. It will once again provide an interface between air pollution health effects research, combustion research, industrial applications, and governmental environmental policy.

\section{Abbreviations}

ADMA-asymmetric dimethylarginie

ADP - adenosinediphosphate

AFM-atomic force microscopy

ALRI-acute lower respiratory infections

AMU-atomic mass units

APCD - air pollution control device

$\mathrm{CHC}$ - chlorinated hydrocarbons

$\mathrm{CMB}$ - chemical mass balance

COPD - chronic obstructive pulmonary disease

CVD—cardiovascular disease

Cyp1a1-cytochrome P450, 1a1gene

DEP_diesel exhaust particulate

EC-elemental carbon

eNOS—nitric oxide synthase 3 (endothelial)

$\mathrm{FP}$-fine particles

NMR_nuclear magnetic resonance

NOC-nano-organic carbon

OC-organic carbon

P2Y12-purinergic receptor P2Y

$\mathrm{PAH}$ - polycyclic aromatic hydrocarbons

PCDD/F-Polychlorinated Dibenzo- $p$-dioxins and

Polychlorinated Dibenzofurans

PFR - persistent free radical

PM-particulate matter

PMF-positive matrix factorization

REMPI-resonance enhanced multiphoton ionization

SERS-surface enhanced raman spectroscopy

SI-spark ignited engines

TC - total carbon

UFPs-ultrafine particles

\section{Acknowledgments}

We would like to acknowledge the sponsors of the conference for their financial and organizational support: Analisi e Monitoraggio del Rischio Ambientale (AMRA), National Research Council of Italy (CNR), Coalition for Responsible Waste Incineration (CRWI), Electric Power Research Institute (EPRI), Louisiana State University (LSU), National Institute of Environmental Health Sciences (NIEHS), National 
Science Foundation (NSF), Universita degli Studi di Napoli Federico II, and University of California-Berkeley

\section{Author Disclosure Statement}

The authors declare that no competing financial interests exist.

\section{References}

Alessandrini, F., Schulz, H., Takenaka, S., Lentner, B., Karg, E., Behrendt, H., and Jakob, T. (2006). Effects of ultrafine carbon particle inhalation on allergic inflammation of the lung. $J \mathrm{Al}$ lergy Clin. Immunol. 117(4):824.

Allouis, C., Beretta, F., and D'Alessio, A. (2003). Structure of inorganic and carbonaceous particles emitted from heavy oil combustion. Chemosphere 51(10), 1091.

Andre, E., Stoeger, T., Takenaka, S., Bahnweg, M., Ritter, B., Karg, E., Lentner, B., Reinhard, C., Schulz, H., and Wjst, M. (2006). Inhalation of ultrafine carbon particles triggers biphasic pro-inflammatory response in the mouse lung. Eur. Respir. J. 28(2):275.

Baulig, A., Garlatti, M., Bonvallot, V., Marchand, A., Barouki, R., Marano, F., et al. 2003. Involvement of reactive oxygen species in the metabolic pathways triggered by diesel exhaust particles in human airway epithelial cells. Am. J. Physiol. Lung C 285(3), L671.

Brimblecombe, P. (1987). The Big Smoke: A History of Air Pollution in London Since Medieval Times. London: Metheun.

Bruce, N., Perez-Padilla, R., and Albalak, R. (2000). Indoor air pollution in developinig countries: a major environmental and public health challenge Bull. World Health Organ. 78(9), 1078.

Cass, G.R., Hughes, L.A., Bhave, P., Kleeman, M.J., Allen, J.O., and Salmon, L.G. (2000). The chemical composition of atmospheric ultrafine particles. Philos. Trans. R. Soc. Lond. 358(1775), 2581.

Chow, J.C., Watson, J.G., Lu, Z.Q., Lowenthal, D.H., Frazier, C.A., Solomon, P.A., et al. 1996. Descriptive analysis of $\operatorname{PM(2.5)}$ and $\mathrm{PM}(10)$ at regionally representative locations during SJVAQS/AUSPEX. Atmos. Environ. 30(12), 2079.

Collina, E., Lasagni, M., Tettamanti, M., and Pitea, D. (2000). Kinetics of MSWI fly ash thermal degradation. 2. Mechanism of native carbon gasification. Environ. Sci. Technol. 34(1), 137.

Cormier, S.A., Lomnicki, S., Backes, W., and Dellinger, B. (2006). Origin and health impacts of emissions of toxic by-products and fine particles from combustion and thermal treatment of hazardous wastes and materials. Environ. Health Perspect. 114(6), 810.

D'Anna, A., Violi, A., D'Alessio, A., and Sarofim, A.F. (2001). A reaction pathway for nanoparticle formation in rich premixed flames. Combust. Flame 127(1-2), 1995.

D'Anna, A., Rolando, A., Allouis, C., Minutolo, P., and D'Alessio, A. (2005). Nano-organic carbon and soot particle measurements in a laminar ethylene diffusion flame. Proc Combust. Inst. 30, 1449.

Deb, S., Chatterjee, M., Bhattacharya, J., Lahiri, P., Chaudhuri, U., Choudhuri, S.P., Kar, S., Siwach, O.P., Sen, P., and Dasgupta, A.K. (2007). Role of purinergic receptors in plateletnanoparticle interactions. Nanotoxicology 1(2):93

Dick, C.A.J., Brown, D.M., Donaldson, K., and Stone, V. (2003). The role of free radicals in the toxic and inflammatory effects of four different ultrafine particle types. Inhal. Toxicol. 15(1), 39.

Donaldson, K., Stone, V., Seaton, A., and Macnee, W. (2001). Ambient particle inhalation and the cardiovascular system: potential mechanisms. Environ. Health Perspect. 109(Suppl 4), 523.
Dvonch, J.T., Brook, R.D., Keeler, G.J., Rajagopalan, S., D'alecy, L.G., Marsik, F.J., et al. (2004). Effects of concentrated fine ambient particles on rat plasma levels of asymmetric dimethylarginine. Inhal. Toxicol. 16(6-7), 473.

Elder, A., Gelein, R., Finkelstein, J., Phipps, R., Frampton, M., Utell, M., et al. (2004). On-road exposure to highway aerosols. 2. Exposures of aged, compromised rats. Inhal. Toxicol. 16, 41.

Gardner, C., Greaves, G.N., Hargrave, G.K., Jarvis, S., Wildman, P., Meneau, F., et al. (2005). In situ measurements of soot formation in simple flames using small angle X-ray scattering. Nuclear Instrum. Methods Phys. Res. 238(1-4), 334.

Harder, V., Gilmour, P.S., Lentner, B., Karg, E., Takenaka, S., Ziesenis, A., et al. 2005. Cardiovascular responses in unrestrained WKY rats to inhaled ultrafine carbon particles. Inhal. Toxicol. 17(1), 29.

Kittelson, D.B., Arnold, M., and Watts, W.F. (1999). Review of Diesel Particulate Matter Sampling Methods. Final Report.

Kleeman, M.J., Schauer, J.J., and Cass, G.R. (2000). Size and composition distribution of fine particulate matter emitted from motor vehicles. Environ. Sci. Technol. 34(7), 1132.

Kuempel, E.D., Tran, C.L., Castranova, V., and Bailer, A.J. (2006). Lung dosimetry and risk assessment of nanoparticles: Evaluating and extending current models in rats and humans. Inhal. Toxicol. 18(10), 717.

Kulkarni, N., Pierse, N., Rushton, L., and Grigg, J. (2006). Carbon in airway macrophages and lung function in children. $N$. Engl. J. Med. 355(1), 21.

Lasagni, M., Collina, E., Ferri, M., Tettamanti, M., and Pitea, D. (1997). Total organic carbon in fly ash from MSW incinerators as a potential combustion indicator: Setting up of the measurement methodology and preliminary evaluation. Waste Manage. Res. 15(5), 507.

Maricq, M.M., Chase, R.E., Podsiadlik, D.H., and Vogt, R. (1999). Vehicle Exhaust Particle Size Distributions: A Comparison of Tailpipe and Dilution Tunnel Measurements. SAE Technical Paper Series. 1999-01-1461.

Marmur, A, Park, S.K., Mulholland, J.A., Tolbert, P.E., and Russell, A.G. (2006). Source apportionment of PM2.5 in the southeastern United States using receptor and emissions-based models: Conceptual differences and implications for time-series health studies. Atmos. Environ. 40(14), 2533.

McCracken, J.M., Smith, K.R., Mittleman, M., Diaz, A., and Schwartz, J. (2007). Chimney stove intervention to reduce longterm woodsmoke exposure lowers blood pressure among Guatemalan women, Environ Health Perspect. 115(7), 996.

Megaridis, C.M., and Dobbins, R.A. (1989). Comparison of soot growth and oxidation in smoking and nonsmoking ethylene diffusion flames. Combust. Sci. Technol. 66(1-3), 1.

Metzger, K.B., Tolbert, P.E., Klein, M., Peel, J.L., Flanders, W.D., Todd, K, et al. (2004). Ambient air pollution and cardiovascular emergency department visits. Epidemiology 15(1), 46.

Mühlberger, F., Streibel, T., Wieser, J., Ulrich, A., and Zimmermann, R. (2005). Single photon ionization time-of-flight mass spectrometry with a pulsed electron beam pumped excimer VUV lamp for on-line gas analysis: Setup and first results on cigarette smoke and human breath. Anal. Chem. 77(22), 7408.

Naeher, L.P., Brauer, M., Lipsett, M., Zelikoff, J.T., Simpson, C.D., Koenig, J.Q, et al. (2007). Woodsmoke health effects: A review. Inhal. Toxic. 19(1), 67.

Oberdörster, G., Oberdörster, E., and Oberdörster, J. (2005). Nanotoxicology: An emerging discipline evolving from studies of ultrafine particles. Environ. Health Perspect. 113(7). 823.

Oudejans, L., Touati, A., and Gullett, B.K. (2004). Real-time, on-line characterization of diesel generator air toxic emissions 
by resonance-enhanced multiphoton ionization time-of-flight mass spectrometry. Anal. Chem. 76(9), 2517.

Peel, J.L., Tolbert, P.E., Klein, M., Metzger, K.B., Flanders, W.D., Todd, K., et al. (2005). Ambient air pollution and respiratory emergency department visits. Epidemiology 16(2), 164.

Peters, A. (2006). When a myocardial infarction comes out of the not-so-blue air. Circulation 114(23), 2430.

Peters, A., Wichmann, H.E., Tuch,T., Heinrich, J., and Heyder, J. (1997). Respiratory effects are associated with the number of ultrafine particles. Am. J. Resp. Crit. Care 155(4), 1376.

Pokhrel, A., Smith, K.R., Khalakdina, A., Deuja, A., and Bates, M.N. (2005). Case-control study of indoor cooking smoke exposure and cataract in Nepal and India, Int. J. Epidemiol. 34, 702.

Pope, C.A. (2000). Epidemiology of fine particulate air pollution and human health: Biologic mechanisms and who's at risk? Environ. Health Perspect. 108, 713.

Pope, C.A., Burnett, R.T., Thun, M.J., Calle, E.E., Krewski, D., Ito, K., et al. (2002). Lung cancer, cardiopulmonary mortality, and long-term exposure to fine particulate air pollution. JAMA 287(9), 1132.

Pugmire, R.J., Solum, M.S., Jiang, J., Sarofim, A.F., Veranth, J., Schobert, H.H., et al. (2002). The study of soot formation by solid state NMR spectroscopy. Abstr. Pap. Am. Chem. S 224, U577.

Radomski, A., Jurasz, P., Alonso-Escolano, D., Drews, M., Morandi, M., Malinski, T., and Radomski, M.W. (2005). Nanoparticle-induced platelet aggregation and vascular thrombosis. Br. J. Pharmacol. 146(6), 882.

Sarnat, J., Marmur, A., Klein, M., Kim, E., Russell, A.G., Sarnat, S.E., Mulholland, J.A., Hopke, P.K., and Tolbert, P.E. (in press). Fine particle sources and cardiorespiratory morbidity: An application of chemical mass balance and factor analytical source apportionment methods. Environ. Health Perspect.

Schnelle-Kreis, J., Sklorz, M., Orasche, J., Stölzel, M., Peters, A., and Zimmermann, R. (2007). Semi volatile organic compounds in ambient PM2.5: Seasonal trends and daily resolved source contributions Environ. Sci. Technol. 41, 3821.
Sklorz, M., Schnelle-Kreis, J., Liu, Y.B., Orasche, J., and Zimmermann, R. (2007a). Daytime resolved analysis of polycyclic aromatic hydrocarbons in urban aerosol samples-Impact of sources and meteorological conditions. Chemosphere 67(5), 934.

Sklorz, M., Briede, J.-J., Schnelle-Kreis, J., Liu, Y., Cyris, J., De Kok, T.M., and Zimmermann, R. (2007b). Concentration of oxygenated polycyclic aromatic hydrocarbons and oxygen free radiacl formation from urban particular matter $J$. Toxicol. Eviron. Health A 70, 1866.

Smith, K.R., Mehta, S., and Maeusezahl-Feuz, M. (2004). Indoor Air Pollution from Household Use of Solid Fuels In: Comparative Quantification of Health Risks: Global and Regional Burden of Disease due to Selected Major Risk Factors. Geneva, World Health Organization, p. 1435.

Stoeger, T., Reinhard, C., Takenaka, S., Schroeppel, A., Karg, E., Ritter, B., et al. (2006). Instillation of six different ultrafine carbon particles indicates a surface area threshold dose for acute lung inflammation in mice. Environ. Health Perspect. 114(3), 328.

Sun, Q.H., Wang, A.X., Jin, X.M., Natanzon, A., Duquaine, D., Brook, R.D., et al. (2005). Long-term air pollution exposure and acceleration of atherosclerosis and vascular inflammation in an animal model. JAMA 294(23), 3003.

Tolbert, P.E., Klein, M., Peel, J., Sarnat, S., and Sarnat, J. (in press). Multipollutant modeling issues in a study of ambient air quality and emergency department visits in Atlanta. J. Expos. Sci. Environ. Epidemiol.

Von Klot, S., Wolke, G., Tuch, T., Heinrich, J., Dockery, D.W., Schwartz, J., et al. (2002). Increased asthma medication use in association with ambient fine and ultrafine particles. Eur. Respir. J. 20(3), 691.

WHO. (2002). World Health Report: Reducing Risks. Geneva: World Health Organization.

Zimmermann, R. (2005). Laser ionisation mass spectrometry for on-line analysis of complex gas mixtures and combustion effluents. Anal. Bioanal. Chem. 381(1), 57. 